\title{
Narcissism, personality traits and Conspicuous Consumption of Brand in Youth
}

\author{
Sabeen Khan, \& Kinza Qaiser \\ Institute of Psychology, Beaconhouse National University
}

\begin{abstract}
The aim of the study was to investigate the relationship among Narcissism, personality traits and conspicuous consumption of brands in youth. This used quantitative research design with a sample consisting of $50 \mathrm{Men}$ and 50 Women. The age ranged between $18-22$ years. A purposive sampling technique was used to select participants. The findings revealed that there was a relationship among conspicuous consumption and traits of personality. It was also uncovered that there are gender differences in conspicuous consumption of brands, narcissism and personality traits. Further it was concluded that narcissism is positively associated with conspicuous consumption of brands. Narcissism was likely to be a positive predictor of conspicuous consumption of brands and personality traits are likely to be a predictor of conspicuous consumption of brands.
\end{abstract}

Keywords: Narcissism, Personality Traits, Conspicuous Consumption 